\title{
Application of Horton's infiltration model for the soil of Dediapada (Gujarat), India
}

\begin{abstract}
M. H. Fadadu
College of Agricultural Engineering and Technology, Dediapada, Navsari Agricultural University, Dediapada (Gujarat), India

P. K. Shrivastava

College of Forestry, Navsari Agricultural University, Navsari (Gujarat), India

D. K. Dwivedi*

College of Forestry, Navsari Agricultural University, Navsari (Gujarat), India

*Corresponding author. E-mail: dhavaldwivedi42@gmail.com

Abstract

The design and evaluation of surface irrigation systems of a site requires reliable data of infiltration which could be provided by an infiltration model. In this study, Horton's infiltration model has been estimated for the soil located in a field of College of Agricultural Engineering and Technology, Dediapada, Gujarat using the infiltration data obtained from several locations in the field using double ring infiltrometer. The decay constant of the Horton's infiltration model was obtained using graphical method and also by using semilog plot of $t$ (time) vs. $(f-f c)$, where $f$ is the infiltration rate $\left(\mathrm{mm} / \mathrm{hr}\right.$ ) and $f_{c}$ is the initial rate of infiltration capacity $(\mathrm{mm} / \mathrm{hr})$. The potential of the Horton's infiltration model so obtained was evaluated by least square fitting with the observed infiltration data. The Horton's infiltration model was used to estimate infiltration rate $(\mathrm{mm} / \mathrm{hr})$ and cumulative infiltration $(\mathrm{cm})$. The Horton's model for infiltration rate obtained by semi-log plot method was obtained as $i=20+94 e^{-1.02 t}$, where $i=$ infiltration rate $(\mathrm{mm} / \mathrm{hr})$ and $t=$ time $(\mathrm{min})$. The coefficient of determination obtained when the infiltration model was applied to observation data taken at various points in the field were found to 0.96 . Therefore, it could be inferred that the Horton's infiltration model could give a reliable estimate of infiltration for the soil of Dediapada.
\end{abstract}

Keywords: Cumulative infiltration, Double ring infiltrometer, Graphical method, Horton's Infiltration model, Infiltration rate

\section{INTRODUCTION}

The flow of water through the surface of the soil is termed as infiltration. The water which is infiltrated replenishes the moisture deficiency in the soil while the excess water which moves downward by gravity force is responsible for building ground water table. Although a negligible proportion of soil water is present on earth compared to the total water present on earth surface, it is of paramount importance for plant life. The infiltration rates are necessary for estimation of groundwater recharge, effective rainfall and effective design of irrigation systems (Michael, 1978). The use of infiltration models in quantifying infiltration plays a major role in watershed management. Also, being one of the most important components of hydrologic cycle, it is becomes essential to estimate infiltration rate and cumulative infiltration for complex analysis of watershed. Efficiency in the application of irrigation water is of great economic importance especially to countries with limited water supplies (Akinbile et al., 2006). The infiltration

\section{Article Info}

DOI: 10.31018/jans.v10i4.1928 Received: October 17, 2018

Revised: November 20, 2018

Accepted: November 27, 2018

\section{How to Cite}

Fadadu, M.H. et al. (2018). Application of Horton's infiltration model for the soil of Dediapada, India. Journal of Applied and Natural Science, 10 (4): $1254-1258$ process of a particular site can be assessed effectively using double ring infiltrometer, however, it becomes a tedious task to obtain infiltration data by this method which can otherwise be obtained in comparatively easier and reliable manner using infiltration model developed for the particular site of study. Therefore, infiltration models should be developed using the infiltration data available for different sites at various antecedent moisture conditions and suitable models should be developed or constants of existing infiltration models should be modified using standard methods. Numerous infiltration models have been used to estimate infiltration rates, however, in this study, only Horton's infiltration model has been evaluated.

Mishra et al. (2003) assessed Horton's infiltration model by conducting various infiltration tests in the laboratory and fields in USA and India. It was concluded from the study that Horton's infiltration model performed satisfactorily with an efficiency of $75 \%$ to $90 \%$. Amin et al. (2006) used Horton's infiltration model to estimate cumulative infiltration at research farm sites of Agricultural and Biore- 
source Engineering Department of Abubakar Tafawa Balewa University (ATBU), Bauchi, Nigeria. The parameters $f c, f_{0}$ and $k$ of the model were found to be $30,65.97$ and -1.73 respectively. When the cumulative infiltration was compared with observed infiltration, the coefficient of determination was found to be 0.893 . T-test results also indicated that Horton's model performed satisfactorily. Zolfaghari et al. (2012) estimated cumulative infiltration for different provinces of Iran with different soils using Horton's infiltration model. The double ring infiltrometer was used to obtain the infiltration rate and cumulative infiltration. It was found that the coefficient of determination of Horton's infiltration model was found to be 0.960 which indicated that cumulative infiltration could be determined reliably by Horton's infiltration model. Sreejani et al. (2017) observed the evaluate infiltration characteristics at five different locations of Andhra University campus using a single and double ring infiltrometer and evaluated Horton's infiltration model. When the observed infiltration data was compared with the estimated infiltration data by Horton's model, it was found that the correlation coefficient was 0.96 and standard error was 2.0. Savasani et al. (2017) evaluated the performance of infiltration models on different soil types in Sangola region in solapur district of Maharashtra state and concluded that Horton's infiltration model performed better than other models like Kostiakov and Green-ampt with a correlation coefficient of 0.98 . The study was undertaken with the objective of obtaining the parameters of the Horton's infiltration model by graphical method and semi-log plot method. The performances of the infiltration equations were compared with the observed infiltration data to obtain the appropriate Horton's infiltration model.

\section{MATERIALS AND METHODS}

Study area: The study was conducted at various sites in a field of College of Agricultural Engineering and Technology, Dediapada Taluka of Narmada district in South Gujarat at $21^{\circ} 66^{\prime \prime} \mathrm{N}$ latitude and $73^{\circ} 59^{\prime \prime}$ longitude with an elevation of $169 \mathrm{~m}$ above mean sea level.

The infiltration data was obtained from infiltration tests conducted by double ring infiltrometer at 10 different locations selected randomly in the field of 1hectare area adjacent to the Agricultural Engineering College building in Dedipada, Gujarat. The soil texture in the field was clay loam. The inner cylinder and outer cylinder used in the double ring infiltrometer test were $30 \mathrm{~cm}$ and $60 \mathrm{~cm}$ in diameter respectively. A buffer pond was created between the cylinders to reduce the loss due to lateral seepage. A hammer was used to drive the cylinders into the soil at $10 \mathrm{~cm}$ depth. The water was filled into the inner cylinder up to the point rod set at desired level and the time interval was not- ed at various intervals as given in Table 1 to obtain the depth of infiltration. The observed infiltration data were used to evaluate the parameters of the Horton's infiltration model which was then used to estimate infiltration data.

Horton (1940) gave the following equation to obtain infiltration rate:

$$
f=f_{c}+\left(f_{0}-f_{c}\right) e^{-k t}
$$

where,

$f=$ infiltration rate at time $\mathrm{t}(\mathrm{mm} / \mathrm{hr})$

$f_{0}=$ initial rate of infiltration capacity $(\mathrm{mm} / \mathrm{hr})$

$f_{c}=$ final constant rate of infiltration at saturation $(\mathrm{mm} / \mathrm{hr})$

$k=a$ constant depending primarily upon soil and vegetation

$e=$ base of the Napierian logarithm

$t=$ time from beginning of the storm (hr)

Horton's model is empirical and it describes the familiar exponential decay of infiltration capacity evident during heavy storms. According to Horton's model, infiltration starts at a constant rate $f_{0}$ and decreases exponentially with time. After some time, when the soil saturation level reaches a certain value, the rate of infiltration becomes equivalent to $f_{c}$.

Infiltration capacity is the maximum rate at which the soil is capable of absorbing water. The term fc denotes it in equation (1). It is also known as final constant rate of infiltration at saturation.

The parameters of Horton's infiltration model were determined in this study using two methods viz. (1) graphical method and (2) semi log plot method.

Graphical method: In this method, a linear graph plot of infiltration rate $(\mathrm{mm} / \mathrm{hr})$ vs. time $t(\mathrm{~min})$ was drawn and the area under the graph $\left(F_{c}\right)$ where the infiltration rate becomes constant was taken. The value of $F_{c}$ is used to obtain the value of the decay constant $k$ in the Horton's equation.

$$
k=\frac{J_{0}-f_{k}}{F_{e}}
$$

The value of $f_{\mathrm{c}}$ was obtained simply by observing the constant values of infiltration rate after a significant time had passed while the value of $f_{o}$ was obtained by projecting the graph on the $y$-axis (infiltration rate). The values of the parameters obtained for the Horton's infiltration model was used to estimate infiltration rate which were compared with the observed infiltration rate. The coefficient of determination was used as the measure of performance. As for accumulated infiltration depth $(F)$, the Horton's equation was integrated using minimum and maximum time limits that were taken during the observation. The accumulated infiltration depth was evaluated using the following equation:

$$
F=\int_{0}^{t} f_{c}+\left(f_{0}-f_{c}\right) e^{-k t} d t
$$

Semi-Log plot method: To obtain the parameters 
of the Horton's model by this method, log is taken on both sides of equation (1).

$$
\begin{aligned}
& \log \left(f-f_{c}\right)=\log \left(f_{0}-f_{c}\right)-k t \log (e) \\
& t=\frac{\log \left(f_{0}-f_{e}\right)}{k \log (e)}-\frac{\log \left(f-f_{c}\right)}{k \log (e)}
\end{aligned}
$$

Equation (4) is in form of a straight line $y=m x+c$ where,

$$
m=-\frac{1}{k \log (\theta)}, y=t \text { and } x=\log \left(f-f_{c}\right)
$$

Semi-log plot of $t$ vs. (f-fc) was used to obtain the required parameters of the Horton's infiltration model. The accumulated infiltration depth was obtained using equation (3) as given in the graphical method. The infiltration equations obtained by both the methods were compared with the observed infiltration data and the coefficient of determination was determined.

\section{RESULTS AND DISCUSSION}

The following average infiltration data were obtained by conducting double ring infiltrometer test at various locations in the field.

Graphical method: Time $t$ (min) vs. $f(\mathrm{~mm} / \mathrm{hr})$ was plotted on a natural graph paper as shown in Fig.2.

The value of $f_{c}$ which is the constant infiltration rate was found to be $20 \mathrm{~mm} / \mathrm{hr}$ and the value of $f_{0}$ was found to be $105 \mathrm{~mm} / \mathrm{hr}$ after projecting the Horton's curve on the y-axis. The shaded area $F_{c}$ was found to be $6120 \mathrm{sq}$. units. The value of $F_{c}$ so obtained was appropriately converted into $\mathrm{mm}$ by multiplying the units of the axes. The final value of $F_{c}$ was evaluated as $102 \mathrm{~mm}$. After substituting the final value of $F_{c}$ in equation, the value of $k$ was found to be 0.93 . Thus, the Horton's equation was obtained in the following form:

$$
f=20+95 e^{-0.92 t}
$$

Where, $t$ is in hours

The equation was used to estimate the infiltration rate $(\mathrm{mm} / \mathrm{hr})$ and it was compared with the observed values taken at two different sites in the field as shown in Fig 3.

$$
F=\int_{0}^{470} 20+95 e^{-0.92 t} d t
$$

The accumulated infiltration $F$ after $t$ hours was obtained after integrating the above equation with limits $t=0$ to $t=470$. It was found that the estimated accumulated infiltration depth and observed infiltration depth were $258.6 \mathrm{~mm}$ and $304 \mathrm{~mm}$ respectively after 7.8 hours.

Semi-Log plot method: The Horton's model parameters were then estimated using semi-log of time $(t)$ vs. $f-f_{c}$ as shown in Fig 4.

The slope of the best fitting line as shown in the Fig. was found to be 135 which was divided by 60 as the $k$ value is to obtained in $\mathrm{hr}^{-1}$ units. Since $f=$ $f_{0}$ when $\mathrm{t}=0, f-f_{c}=f_{0}-f_{c}$.

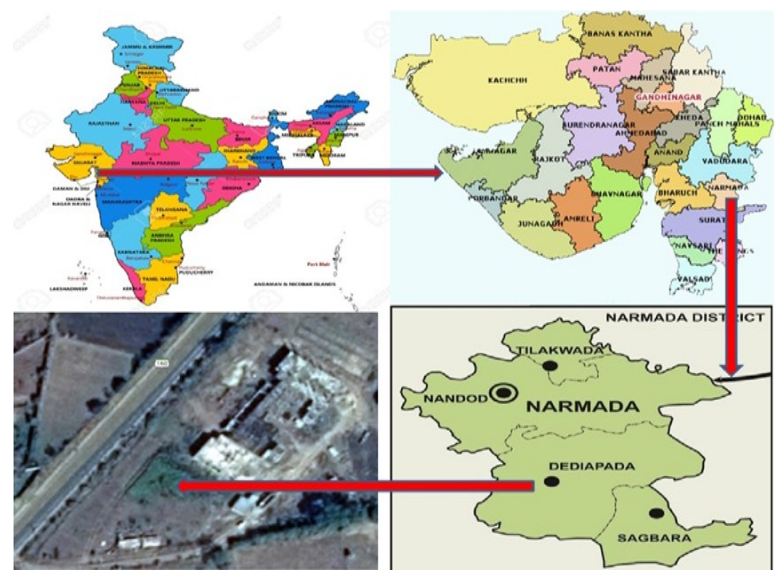

Fig. 1. Location of the study area.

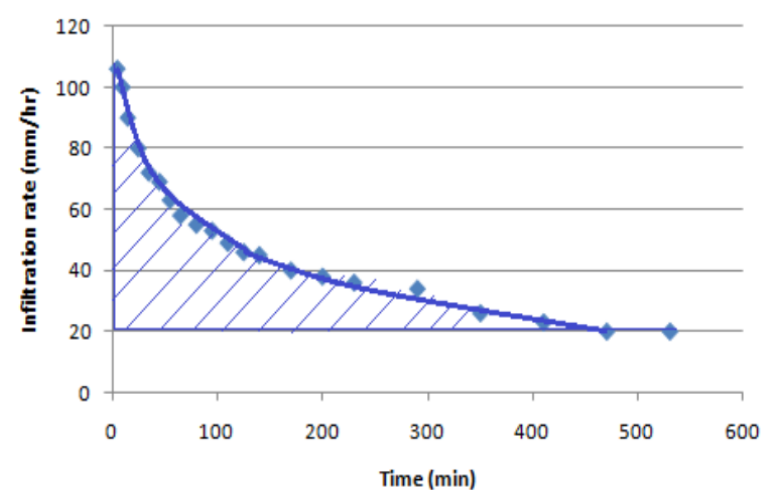

Fig. 2. Horton's infiltration curve showing infiltration rates at various times.
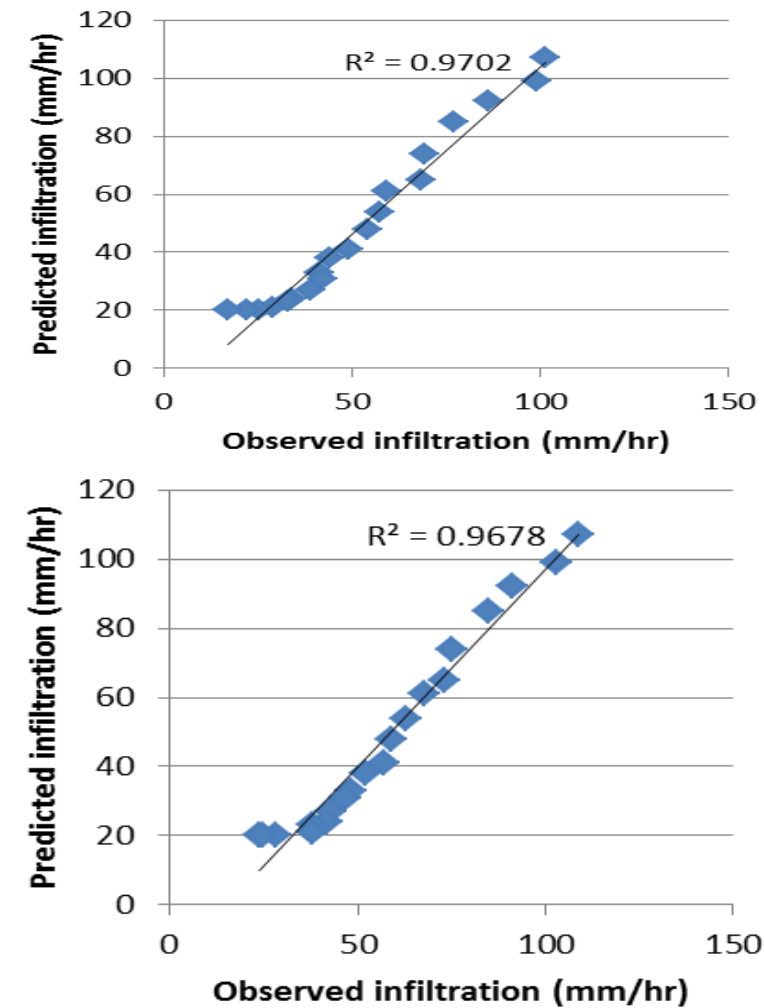

Fig. 3. Comparison of observed and predicted infiltration rate (Horton's graphical method). 
Fadadu, M.H.. et al. / J. Appl. \& Nat. Sci. 10 (4): 1254-1258 (2018)
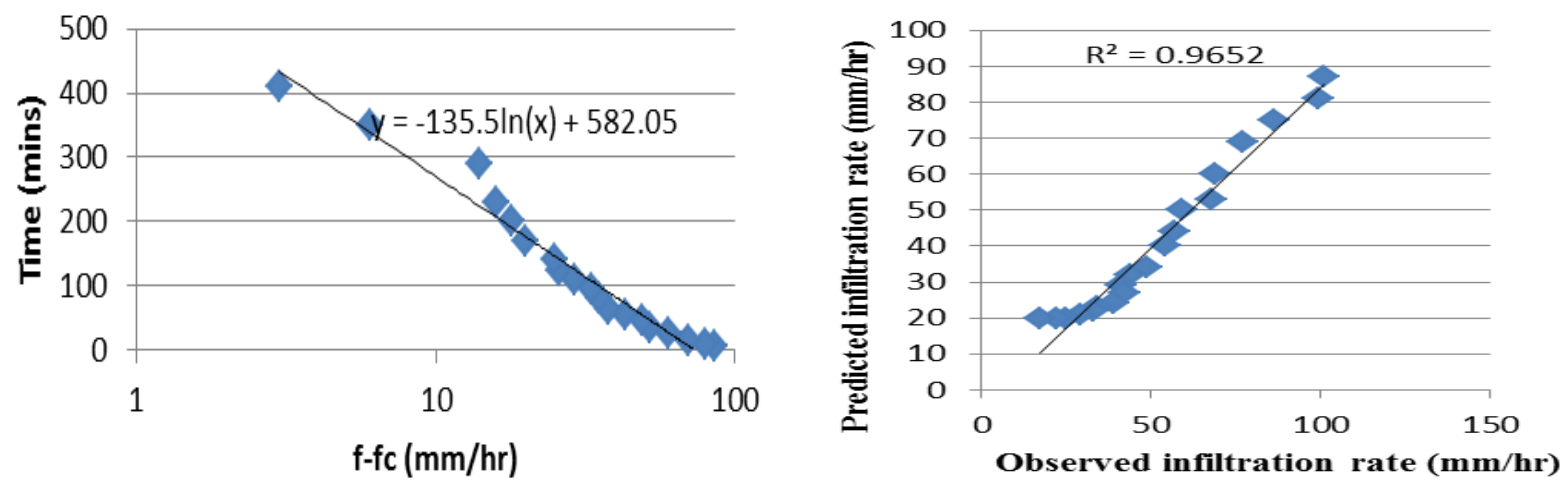

Fig. 4. Time $t$ ( $\mathrm{min})$ vs. infiltration rate $\mathrm{f}$-fc $\mathrm{mm} / \mathrm{hr}$.

$$
\begin{aligned}
& m=-\frac{135}{60}=-\frac{1}{k \log (e)} \\
& \therefore k=\frac{1}{2.25 \times 0.434}=1.02
\end{aligned}
$$

Also from the graph, when $t=0, f_{0}-f_{c}=74$.

$$
\begin{aligned}
& f-f_{c}=74=f_{0}-f_{c} \\
& \therefore f_{0}=74+f_{c}=74+20=94
\end{aligned}
$$

The following Horton's equation for infiltration rate is obtained.

$$
f=20+94 e^{-1.02 t}
$$

The above equation was used to estimate the infiltration rate which was compared with the observed infiltration rate taken at two sites in the field as shown in Fig. 5.

$$
F=\int_{0}^{470} 20+94 e^{-1.02 t} d t
$$

The accumulated infiltration $F$ after $t$ hours was obtained after integrating the above equation with limits $t=0$ to $t=470$. It was found that the estimated

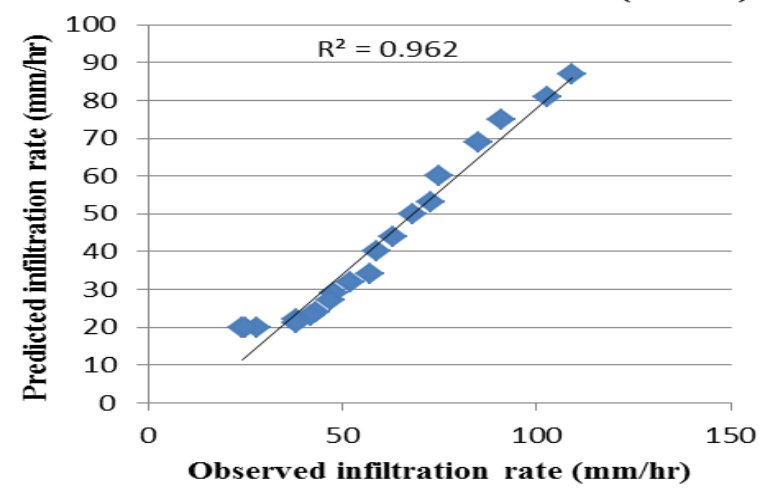

Fig. 5. Observed vs. predicted infiltration rate (log plot method).

accumulated infiltration depth and observed infiltration depth were $248.7 \mathrm{~mm}$ and $304 \mathrm{~mm}$ respectively after 7.8 hours.

It was observed from the study that the coefficient

\begin{tabular}{|c|c|c|c|c|c|c|}
\hline $\begin{array}{l}\text { Time } \\
t \text { (min) }\end{array}$ & $\begin{array}{l}\text { Before } \\
\text { filling }\end{array}$ & $\begin{array}{l}\text { After } \\
\text { filling }\end{array}$ & $\begin{array}{l}\text { Infiltration } \\
\text { depth } d(\mathrm{~mm})\end{array}$ & $\begin{array}{l}\text { Infiltration rate } \\
f(\mathrm{~mm} / \mathrm{hr})\end{array}$ & $\begin{array}{l}\text { Cumulative infil- } \\
\text { tration } F(\mathrm{~mm})\end{array}$ & $\begin{array}{l}f \boldsymbol{f} f_{c}(\mathrm{~mm} / \\
\mathrm{hr})\end{array}$ \\
\hline 5 & 141 & 150 & 9 & 106 & 9 & 86 \\
\hline 10 & 142 & 150 & 8 & 100 & 17 & 80 \\
\hline 15 & 143 & 150 & 8 & 90 & 25 & 70 \\
\hline 25 & 137 & 150 & 13 & 80 & 38 & 60 \\
\hline 35 & 138 & 150 & 12 & 72 & 50 & 52 \\
\hline 45 & 139 & 150 & 12 & 69 & 61 & 49 \\
\hline 55 & 140 & 150 & 11 & 63 & 72 & 43 \\
\hline 65 & 140 & 150 & 10 & 58 & 82 & 38 \\
\hline 80 & 136 & 150 & 14 & 55 & 95 & 35 \\
\hline 95 & 137 & 150 & 13 & 53 & 109 & 33 \\
\hline 110 & 138 & 150 & 12 & 49 & 121 & 29 \\
\hline 125 & 139 & 150 & 12 & 46 & 133 & 26 \\
\hline 140 & 139 & 150 & 11 & 45 & 144 & 25 \\
\hline 170 & 130 & 150 & 20 & 40 & 164 & 20 \\
\hline 200 & 131 & 150 & 19 & 38 & 183 & 18 \\
\hline 230 & 132 & 150 & 18 & 36 & 201 & 16 \\
\hline 290 & 116 & 150 & 34 & 34 & 235 & 14 \\
\hline 350 & 124 & 150 & 26 & 26 & 261 & 6 \\
\hline 410 & 127 & 150 & 23 & 23 & 284 & 3 \\
\hline 470 & 130 & 150 & 20 & 20 & 304 & 0 \\
\hline 530 & 130 & 150 & 20 & 20 & 324 & 0 \\
\hline
\end{tabular}
of determination obtained on comparison of observed and predicting infiltration rates was found to be 0.96 and therefore it can be concluded that the Horton's infiltration model could be used to

Table 1. Infiltration data obtained by double ring infiltrometer test. 
estimate infiltration rate. However, the parameter of models are site specific and therefore the model should not used on other sites without making necessary modifications. Ajayi et al. (2016) also evaluated the decay constant $k$ of the Horton's infiltration model and obtained different values for sandy soils at the Department of Agricultural Engineering experimental field, Samaru, Zaria, Nigeria. They concluded that the semi log plot method was less error prone compared to the graphical method. Sreejani et al. (2017) and Savasani et al. (2017) had also obtained high correlation coefficient of 0.96 and 0.98 respectively, for clay loam soils at Andhra University Campus, Visakhapatnam and Sangola region in solapur district of Maharashtra state respectively, after comparing estimated infiltration by Horton's model with the observed values. The results obtained in this study also revealed that high correlation coefficients were obtained when the Horton's model was used to simulate infiltration data and both method of obtaining parameters of the Horton's model could be successfully used for simulating infiltration rate as indicated by high coefficient of determination values.

\section{Conclusion}

The tedious task obtaining infiltration data on the same field for different experiments and analysis could be minimized by making use infiltration model such as Horton's infiltration model. In order to obtain the value of the decay constant in the Horton's infiltration model, two methods namely graphical and semi log method were used and it was concluded that the decay constant $k$ was in both the methods were found to be close to each other. Also the Horton's infiltration model obtained by both the methods exhibited reliable perfor- mance when compared with the observed infiltration data. The Horton's model for infiltration rate obtained by semi-log plot method was obtained as $i=20+94 e^{-1.02 t}$, where $i=$ infiltration rate $(\mathrm{mm} / \mathrm{hr})$ and $t=$ time $(\mathrm{min})$.

\section{REFERENCES}

1. Ajayi A. S., Brai M. A., Eriakha E. C., and Ehiomogue P. (2016) Evaluation of Methods for Estimating the Decay Constant (K) of Horton's Infiltration Model, International Journal of Interdisciplinary Research and Innovations, 4(2): 13-18.

2. Akinbile C. O. (2010). Comparative analysis of infiltration measurements of two irrigated soils in Akure, Nigeria. J. Applied Sci. Eng. Technol, 10: 7-12.

3. Amin S. A., Abubakar N. A., Usman D. D., Abdullahi A. S. and Yakubu M. A. (2017). Comparative evaluation of selected infiltration models for estimating soil cumulative infiltration. Global Scientific Journals, 5 (12): 1.

4. Michael, A. M. (1978). Irrigation: theory and practice. Vikas publishing house.

5. Horton, R. E. 1940. An approach towards a physical infiltration capacity. Soil Science Society of America Proceedings, Vol. 5: 399-417.

6. Mishra S. K., Tyagi J. V., and Singh V. P. (2003). Comparison of infiltration models. Hydrological processes, 17(13): 2629-2652.

7. Savasani R., Chudasama, K., and Gundali, M (2017). Performance of Infiltration Models on Different Soil Types, International Journal of Innovative and Emerging Research in Engineering, 4(1): 93-96.

8. Sreejani T.P., Abhishek D., Srinivas Rao G.V. R., and Abbulu Y. (2017) A Study on Infiltration Characteristics of Soils at Andhra University Campus, Visakhapatnam, International Journal of Environmental Research and Development, 7(1): 29-44.

9. Zolfaghari, A. A., S. Mirzaee and M.Gorji (2012). Comparison of different models for estimating cumulative infiltration. Int. J. Soil Sci., 1 - 8. 